$\mathrm{BDX}-613-1491$

Distribution Category UC-38

\title{
ANALYSIS OF THICK FILM CONDUCTOR INKS
}

Published September 1976

Project. Leader:

D. H. Brewer

Department 816

Project Team:

L. L. Lantz

PDO 6984903

Topical Report

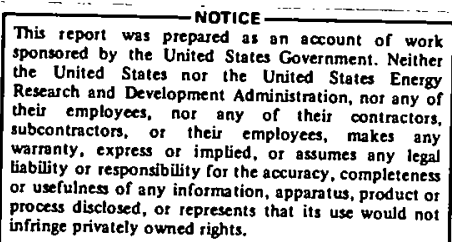




\section{DISCLAIMER}

This report was prepared as an account of work sponsored by an agency of the United States Government. Neither the United States Government nor any agency Thereof, nor any of their employees, makes any warranty, express or implied, or assumes any legal liability or responsibility for the accuracy, completeness, or usefulness of any information, apparatus, product, or process disclosed, or represents that its use would not infringe privately owned rights. Reference herein to any specific commercial product, process, or service by trade name, trademark, manufacturer, or otherwise does not necessarily constitute or imply its endorsement, recommendation, or favoring by the United States Government or any agency thereof. The views and opinions of authors expressed herein do not necessarily state or reflect those of the United States Government or any agency thereof. 


\section{DISCLAIMER}

Portions of this document may be illegible in electronic image products. Images are produced from the best available original document. 


\section{ANALYSIS OF THICK FILM CONDUCTOR INKS}

BDX-613-1491, UNCLASSIFIED Topical Report, Published September 1976

Prepared by D. H. Brewer, D/816, under PDO 6984903

This project was undertaken to determine what ink characteristics influenced fired films and to see what analytical methods had been used to characterize inks and films. The analytical methods used were thermogravimetric analysis, pyrolysis-gas chromatography, infrared spectrophotometry, mass spectrometry, atomic absorption spectrophotometry, scanning electron microscopy with energy dispersive $X$-ray spectroscopy, and particle size analysis using a Coulter counter.

WPC-sp

This report was prepared as an account of work sponsored by the United States Government. Neither the United States nor the United States Energy Research and Development Administration, nor any of their employees, nor any of their contractors, subcontractors, or their employees, makes any warranty, express or implied, or assumes any legal liability or responsibility for the accuracy, completeness or usefulness of any information, apparatus, product or process disclosed, or represents that its use would not infringe privately owned rights.
THE BENDIX CORPORATION

KANSAS CITY DIVISION

P.O. BOX 1159

KANSAS CITY, MISSOURI 64141

A prime contractor for the United States Energy Research and Development Administration Contract Number E(29-1)-613 USERDA 
CONTENTS

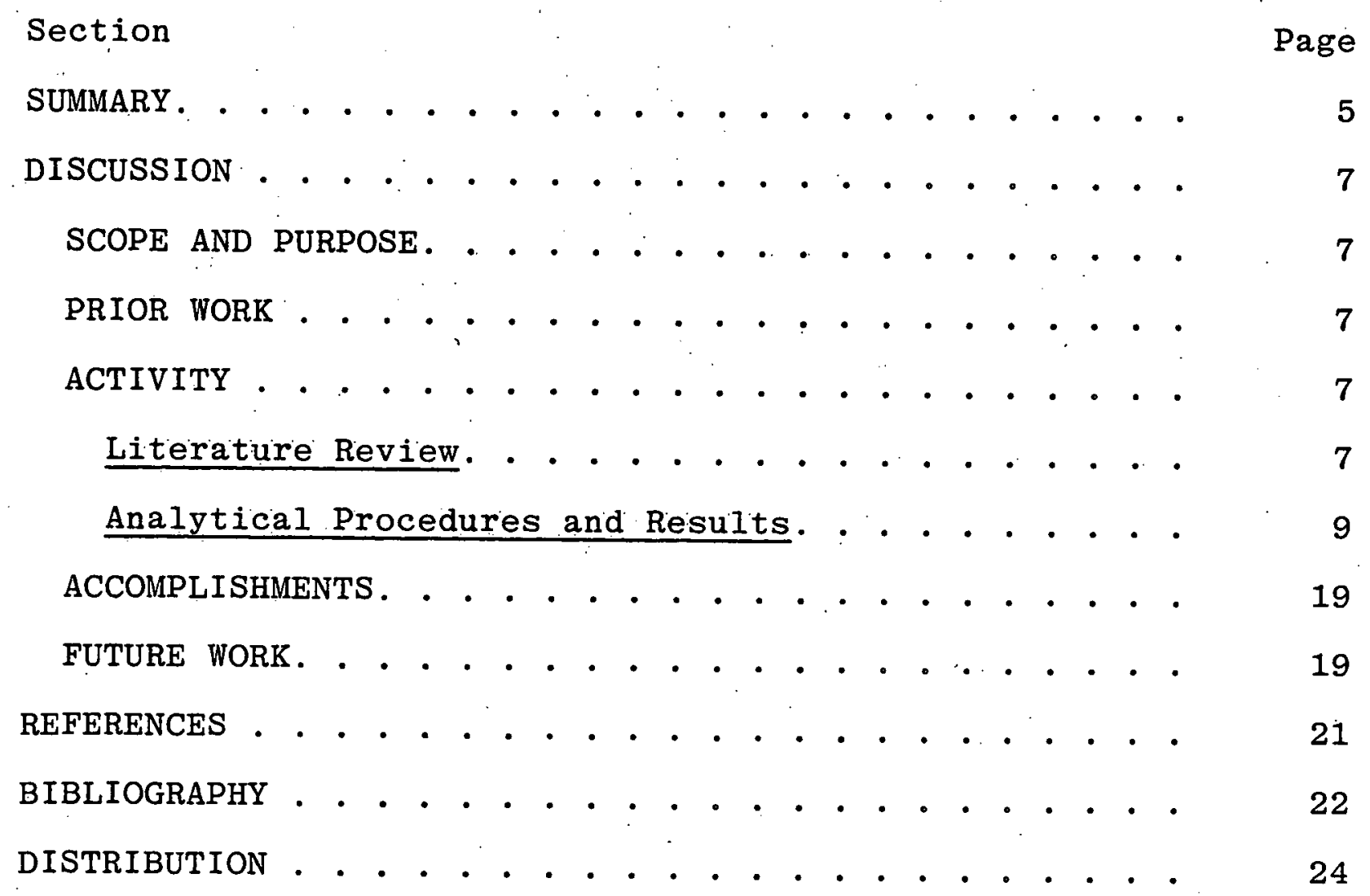




\section{ILLUSTRATIONS}

Figure

Page

1

IR Fingerprint of Thick Films. . . . . . . .

Pyrolysis-GC Fingerprint of Thick Films. . .

\section{TABLES}

Reference Identification of Ink Composition

Factors Influencing Fired Film Factors...

Thermogravimetric Analysis of Conductor Inks . . . . . . . . . . . . . . . . . .

Atomic Absorption Analysis of Thick

Film Conductor Inks. . . . . . . . . . . . 
Thick film inks can be used to produce conductors, resistors, and dielectrics. The inks are a mixture of organic liquids and inorganic particles. They are screen printed, dried, and fired to produce hybrid microcircuits. Drying and firing volatilizes the organic materials leaving the printed network adhering to an aluminum oxide substrate by a glass phase interaction.

In many situations inks can be used instead of vacuum evaporated thin film circuitry. Where inks are used exclusively, the cost of producing thick film circuits is lower than producing evaporated circuits primarily because of the cost of equipment. The thick film method is also more easily adapted to continuous operation.

Bendix activity in thick films was initiated in $1967 .{ }^{1}$ This particular study was undertaken as a result of processing difficulties which occur during the thermal compression (TC) bonding of fine wires to capacitors having thick film terminations. The primary objective of this study. was to identify the variables within thick film pastes which affect TC bonding. Another objective was to become familiar with the initial conductor materials so that successful bonding could be done. Sandia Laboratory, Albuquerque has since considered thick films as a replacement for some circuits presently produced using thin film methods. The decision to use thick films is pending the results of an extensive study of these materials. With the advent of the Sandia study and the potential use of thick films in production circuits, the Bendix analytical capability is being used to supplement Sandia's capability and a joint effort is being made to decide what receiving inspection methods should be used to assure lot to lot uniformity.

An extensive literature search was performed. The articles, reports, and books reviewed in this search are listed in the Bibliography. The purpose of the search was to determine what ink characteristics influenced the fired film and to see what analytical methods had been used in characterizing the inks.

Laboratory tests were performed. Analysis was divided into two fclassifications, organics and inorganics. The methods applied to the analysis of the organics were thermogravimetric analysis (TGA), pyrolysis-gas chromatography (P-GC), infrared spectrophotometry (IR), and mass spectroscopy (MS). The methods applied to inorganics were scanning electron microscopy/energy dispersive $x$-ray spectrometry (SEM/EDAX), atomic absorption spectrophotometry ( $\mathrm{AA})$, and analysis using a Coulter Electronics counter. 
The organic component in most inks is a complex mixture of pine oils and resins which vary from lot to lot with each manufacturer. This variation does not affect the properties of the fired film but may affect printing characteristics: The temperatures at which the organics volatilize are important in drying and firing. Thermogravimetric analysis is capable of measuring the temperature at which various components volatilize and the weight percent volatilization. Pyrolysis-gas chromatography and infrared spectrophotometry are methods that identify groups of compounds without giving an explicit composition. TGA, P-GC, and IR are "fingerprinting" techniques which detect some facet of lot to lot variation. Qualitative analyses were made using the mass spectrograph but this does not appear to be necessary to assure sufficient lot to lot uniformity. Thermogravimetric analysis is recommended as the receiving inspection method for the organic component .

The inorganic portion of the ink consists of particles of metal, glass, and flux. The scanning electron microscope/energy dispersive $x$-ray analyzer was used to view individual particles and analyze their composition. Atomic absorption spectrophotometry was used to obtain a quantitative chemical analysis of metal, glass, and flux combined. The Coulter counter was used to measure the particle size distribution of the metal, glass, and flux in combination. Coulter counter and AA analyses are recommended as the receiving inspection methods for the inorganic component. 


\section{DISCUSSION}

\section{SCOPE AND PURPOSE}

A process development project, Thick Film Bonding, PDO 6984903, was started as a result of difficulty in bonding fine wire to hybrid microcircuit applique capacitors with thick film terminations. This work has been supported by that PDO. To overcome the bonding problems, better understanding was needed of conductor ink properties and processing factors which influence bondability.

When Sandia Laboratory, Albuquerque considered thick film inks for application in production circuits, consideration was given to test methods that could be used to monitor lot to lot uniformity. Therefore, the purpose of this study was to determine what factors influence the bondability of fired films and what tests would best, monitor lot uniformity. The materials studied were limited to conductor inks.

\section{PRIOR WORK}

No prior work has been done at Bendix Kansas City, but publications contain information about various facets of thick film technology. The reference section contains a listing of articles from which information was cited in Literature Review. A more complete listing of literature is contained in the Bibliography.

\section{ACTIVITY}

\section{Literature Review}

A literature review was performed to determine what constituents might be present in the inks and what influence these constituents have on processing and the fired films. The articles were also reviewed to see what analytical methods had been used to obtain the data that were presented.

Adhesion of the fired film to the substrate is influenced by substrate composition. Aluminum oxide is generally used as the substrate material. Ninety-six percent $\mathrm{Al}_{2} \mathrm{O}_{3}$ is usually chosen because it offers the best compromise between adhesion and strength. Ninety-two percent $\mathrm{Al}_{2} \mathrm{O}_{3}$ has better adhesion properties because it has more flux at the grain boundaries. Ninety-eight percent $\mathrm{Al}_{2} \mathrm{O}_{3}$ is the strongest because it has the least flux at the grain boundaries. Ink manufacturers have generally chosen 96 percent $\mathrm{Al}_{2} \mathrm{O}_{3}$ around which to design their inks. The main fluxing constituents in the $\mathrm{Al}_{2} \mathrm{O}_{3}$ are usually a mixture of $\mathrm{SiO}_{2}$ and $\mathrm{MgO}$ or $\mathrm{CaO}^{2}{ }^{2}{ }^{3}$ 
One study ${ }^{3}$ observed that the best adhesion was obtained only when inks displayed a particular glass structure. The glass structure was revealed by removing the metal phases leaving the glass in those areas where it was bonded to the substrate. Adhesion degrades under conditions of rapid temperature cycling because of the expansion mismatch between the conductor and substrate. Adhesion degradation can also be caused by elevated temperature storage when intermetallic compounds are formed. The intermetallic compounds increase in volume which induces stress which is thought to weaken the glass-metal network.

In general, metal or metal oxide particles form the conducting phase. Glass forming metal oxides bind the conductive phase together and to the substrate. The screening vehicle is an organic material which contains wetting agents for the particles and a solvent which is used to adjust viscosity. ${ }^{2}$ Conductor inks contain $\mathrm{Au}, \mathrm{Pt}_{2}, \mathrm{Pd}_{3}$ and $\mathrm{Ag}$ depending on the properties required

Because metal particles are fine and voids small, the glass phase must be extremely fluid at firing temperatures to flow through the pores. The necessary fluidity is obtained by use of a lead borosilicate glass with low silica content. A typical composition of glass oxides is lead, boron, silicon, and bismuth at 30 , 35,10 , and 25 weight percent respectively.

Sometimes small additions of cadmium oxide are made or the lead is replaced by cadmium. This is claimed to improve adhesion and solderability. Bismuth oxide, not normally included in the glass frit, but added as a separate powder, further lowers the viscosity of the glass and may also act as a fiux which dissolves the glassy phase in the ceramic. This helps to improve the adhesion to the substrate. ${ }^{7}$

Thick film conductors (fritless) which adhere to the substrate in a different way have been more recently developed. Adhesion with this material is obtained by reactive bonding. A base metal is introduced as an element alloyed with the precious metal. On firing, the base metal oxidizes at the particle surface and chemically attacks the alumina in the substrate to form a bond. 7

The structure of a fired conductor is a partially sintered network of metal particles attached to the substrate by a glassy layer. The glassy layer penetrates voids in the metal layer which are grain boundary regions in the substrate and wets the substrate surface. Since the glass does not chemically bond to the precious metal or wet the metal surface, adhesion depends on the mechanical linkage formed by the penetration of the glass into the metal network. The metal film must have some degree of
porosity. 
Table 1 summarizes the factors of ink composition which influence the fired film and lists the reference in which the assertion was made.

The organic portion (two components) of the ink does not influence the fired film but does influence its processing. There are two purposes served by the organic constituent. It is a vehicle or viscosity adjuster which is driven off during a drying operation. This component is volatile at about $100^{\circ} \mathrm{C}$. It is also a binder which holds the glass and metal in position during the firing operation. This component generally volatilizes at about $300^{\circ} \mathrm{C}$. In order to obtain a material which performs these functions, ink manufacturers use a complex mixture of various materials as shown in this report.

The analytical methods are optical and scanning electron microscopy for observation of particulates; gas chromatography for analysis of the organic component; $x$-ray spectroscopy for the detection of elements present in quantities greater than 1 percent; atomic absorption spectrophotometry to determine quantitatively the composition of the inorganic constituents; and $x$-ray diffraction to determine changes in crystallinity. ${ }^{2}$

\section{Analytical Procedures and Results}

Review of the literature shows that the ink characteristics affecting the fired film were chemical composition, glass/metal ratio, particle size distribution, and particle shape. In addition, processing is influenced by the organic constituents.

Analyses of the inks were divided between analyses of the organic and inorganic constituents. Analysis of the organic constituents were performed using thermogravimetric analysis, infrared spectrophotometry, pyrolysis-gas chromatography, and mass spectroscopy. Thermogravimetric analysis measures the temperature at which a volatile component departs and the weight loss at that temperature. By this method, the weight percent of vehicle and binder can be determined and, by difference, the weight percent inorganics. Infrared spectrophotometry and pyrolysis-gas chromatography are methods which identify the organics present by group rather than by individual components as does the mass spectrograph. IR and Pyrolysis-GC can produce a fingerprint with which subsequent fingerprints can be compared to determine that no more or less groups are present.

Analyses of the inorganic constituents were performed using the scanning electron microscope/energy dispersive x-ray analyzer (SEM/EDAX), Coulter counter, and atomic absorption spectrophotometer (AA). The SEM/EDAX is used to photograph the particles 
Table 1. Reference Identification of Ink Composition Factors Influencing Fired Film Factors

\begin{tabular}{|c|c|c|c|c|}
\hline Conditions & $\begin{array}{l}\text { Conductor/ } \\
\text { Glass Ratio }\end{array}$ & $\begin{array}{l}\text { Chemical } \\
\text { Composition }\end{array}$ & $\begin{array}{l}\text { Particle } \\
\text { Size } \\
\text { Dist. }\end{array}$ & $\begin{array}{l}\text { Particle } \\
\text { Shape }\end{array}$ \\
\hline Conductivity & 7,8 & 7 & 6,7 & 7 \\
\hline Adhesion & & 7 & & \\
\hline $\begin{array}{l}\text { Temperature } \\
\text { Coefficient } \\
\text { of Resistivity }\end{array}$ & 8 & 7 & 6 & \\
\hline Solderability & & 7 & & \\
\hline Bondability & & 7 & & \\
\hline
\end{tabular}

to show particle shapes and analyze the individual particles to determine their composition. The Coulter counter measures the particle size distribution. The AA spectrophotometer is used to obtain a quantitative chemical analysis of all solids combined.

Thermogravimetric Analysis

Thermogravimetric analyses were performed with a du Pont Thermogravimetric Analyzer Model 951. Samples weighing about $20 \mathrm{mg}$ were placed in a platinum pan and weighed. The test was performed in a dry nitrogen atmosphere with heating from $26^{\circ} \mathrm{C}$ to $850^{\circ} \mathrm{C}$ at the rate of $10^{\circ} \mathrm{C} / \mathrm{min}$. (Table 2 ).

Infrared Spectrophotometer

The IR analyses were performed using a Perkin-Elmer Grating Infrared Spectrophotometer, Model 457. Samples were dissolved in tetrahydrofuran and filtered several times until a fairly clear filtrate was obtained. The filtrate was placed on a potassium bromide plate and heated to evaporate the solvent. IR spectra was obtained from the residue (Figure 1).

Pyrolysis-Gas Chromatography

Pyrolysis-GC was performed using a Chemical Data System Pyroprobe, Model 190 and a Perkin-Elmer Gas Chromatograph, Model 900 (Figure 2). The specimen was placed on a platinum ribbon in the Pyroprobe which was operated with a ramp of $10^{\circ} \mathrm{C} / \mathrm{ms}$, an interval of 5 seconds, and a final temperature of $900^{\circ} \mathrm{C}$. The following instrument settings were used: 
Table 2. Thermogravimetric Analysis of Conductor Inks

\begin{tabular}{|c|c|c|c|c|}
\hline \multirow[b]{2}{*}{ Material. } & \multicolumn{2}{|c|}{ Vehicle } & \multicolumn{2}{|l|}{ Binder. } \\
\hline & $\begin{array}{l}\text { Mass } \\
\text { (pbw) }\end{array}$ & $\begin{array}{l}\text { Volatilizes } \\
\left({ }^{\circ} \mathrm{C}\right)\end{array}$ & $\begin{array}{l}\text { Mass } \\
(\mathrm{pbw})\end{array}$ & $\begin{array}{l}\text { Volatilizes } \\
\left({ }^{\circ} \mathrm{C}\right)\end{array}$ \\
\hline $\begin{array}{l}\text { duPont* } \\
8653\end{array}$ & 8 & 70 & 2 & 315 \\
\hline $\begin{array}{l}\text { ESL** } \\
5800\end{array}$ & 10.5 & 75 & 2.5 & 315 \\
\hline $\begin{array}{l}\text { TFS*** } \\
3104\end{array}$ & 9 & 99 & 3 & 310 \\
\hline $\begin{array}{l}\text { TFS } \\
3007\end{array}$ & 10 & 100 & 3 & 325 \\
\hline
\end{tabular}

*E. I. du Pont de Nemours and Company, Incorporated Photo Products Department Electronic Materials Division **Electro-Science Laboratories, Incorporated ***Thick Film Systems., Incorporated

$\begin{array}{ll}\text { Injector temperature } & 110^{\circ} \mathrm{C}, \\ \text { Column temperature } & 90^{\circ} \mathrm{C}, \\ \text { Manifold temperature } & 250^{\circ} \mathrm{C}, \\ \text { Hot wire detector temperature } & 250^{\circ} \mathrm{C}, \\ \text { Helium flow rate program } & 30,000 \mathrm{~mm}^{3} / \mathrm{minute}, \\ \text { Column heating rate } & 12^{\circ} \mathrm{C} / \mathrm{minute}, \\ \text { Initial temperature } & 90^{\circ} \mathrm{C}, \\ \text { Sample size } & 20 \mathrm{mg}, \\ \text { Final temperature } & 200^{\circ} \mathrm{C}, \\ \text { Column size } & 6 \mathrm{feet}(152 \mathrm{~cm}), \text { and } \\ \text { Liquid phase } & \mathrm{SE}-30\end{array}$



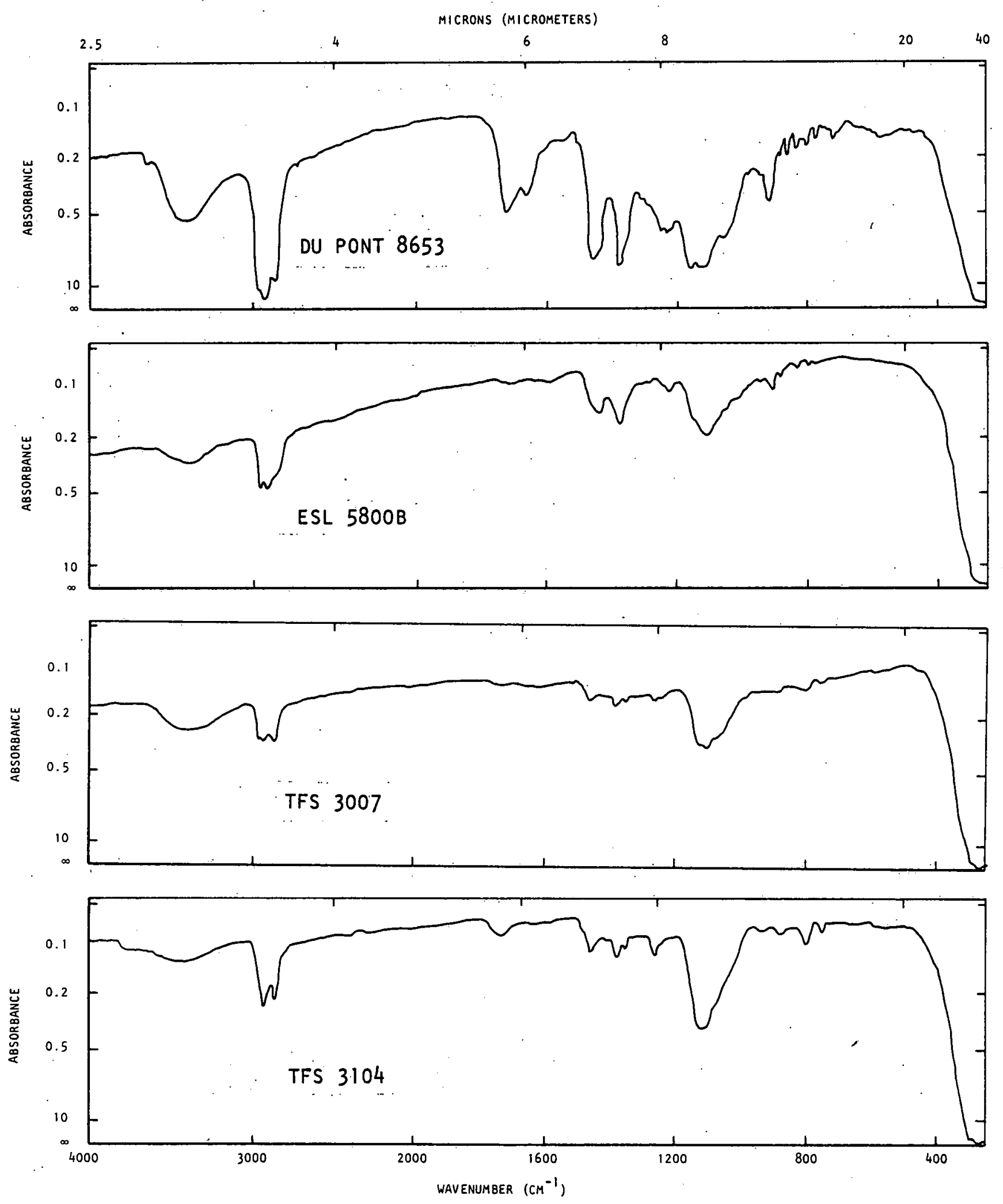

Figure 1. IR Fingerprint of Thick Films 

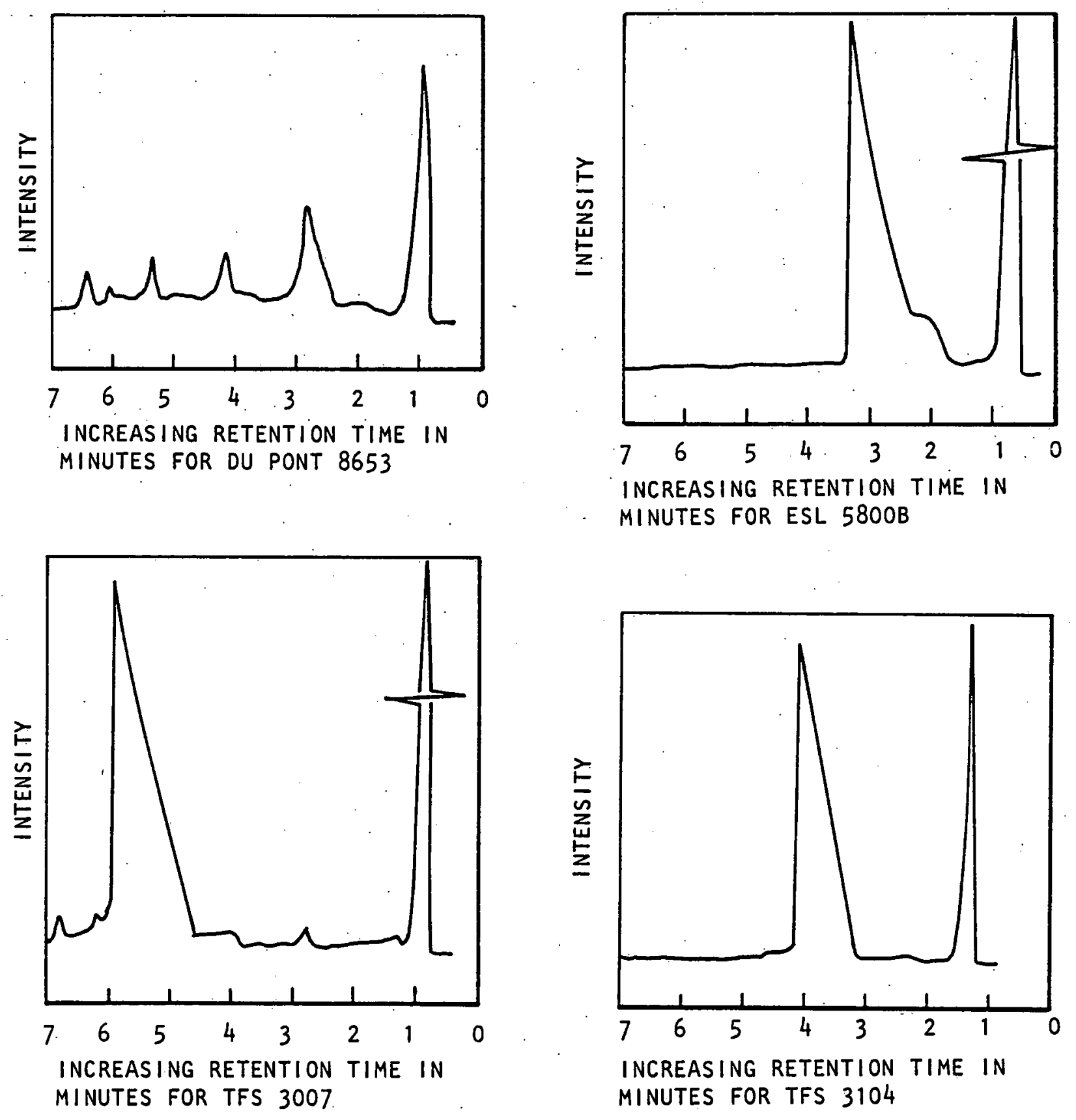

Figure 2. Pyrolysis-GC Fingerprint of Thick Films 


\section{Mass Spectroscopy}

Mass spectrometric analysis was performed using a CEC 21-110C mass spectrometer. The sample was placed in the source at room temperature and raised through $300^{\circ} \mathrm{C}$. The vacuum in the source was in the $1 \times 10^{-6}$ torr range $(133 \mu \mathrm{Pa})$.

The following is a listing of components detected in three inks. Composition of ESL 5800B

Terpenes--unsaturated hydrocarbons with an empirical formula of $\mathrm{C}_{10} \mathrm{H}_{16}$.

Terpinols--empirical formula of $\mathrm{C}_{10} \mathrm{H}_{17} \mathrm{OH}$.

A carbonate.

Naphthyl--indene compounds-unsaturated cyclic hydrocarbons:

Alcohols--short chained and long chained (straight and branched chains).

Ether-glycol compounds.

Cellosolve acetate--ethylene glycol alkyl ether.

Straight chain and branched hydrocarbons.

Composition of du Pont 8653

Terpenes.

Terpinols.

Rosin oils--dihydro, dehydro, and normal abietic acids.

Turpentine--terpenes.

Cellosolve acetate.

Alcohols--straight chained and branched alcohols--not aromatic.

Straight chained and branched hydrocarbons.

Composition of Partilok (TFS) Lot 4184

This material was found to be straight polyethylene glycols with many dimethyl terminations. 


\section{Scanning Electron Microscopy/Energy Dispersive X-Ray Analysis}

Scanning electron micrographs (Figure 3) and EDAX data were taken at an accelerating voltage of $25 \mathrm{kV}$. Specimens were prepared by washing a quantity of ink with isopropyl alcohol through a $0.4 \mu \mathrm{m}$ Miliipore filter. A $10 \mathrm{~mm}$ diameter circle was removed from the filter paper for SEM/EDAX analyses and the remainder was used to obtain a specimen for the coulter counter.

\section{Coulter Counter Particle Size Distribution}

To prepare the Coulter counter specimen, a piece of $0.4 \mu \mathrm{m}$ filter paper containing the remains after the alcohol wash was placed in a beaker with some standard saline solution and ultrasonically agitated. A small amount of this solution was introduced into the Coulter counter where a $70 \mu \mathrm{m}$ diameter orifice was used to determine the particle size distribution (Figure 4 ).

\section{Atomic Absorption Analysis}

Atomic absorption analysis is used to quantitatively measure the metal composition of the inorganic particles of the thick film conductor inks. A procedure was developed for preparing samples of the conductor ink particles prior to atomic absorption analysis, and the appropriate procedures were determined for making the atomic absorption measurements.

The first step in the sample preparation is to separate the ink particles from the organic phase, since this material is not attacked by the acids used to dissolve the particulates. A 30 to $70 \mathrm{mg}$ ink sample is dispersed in 20 cubic millimeters of ethanol to dissolve the organic material. This step is carried out with the aid of ultrasonics to speed the dissolution process and to keep the particles dispersed in the ethanol. The dispersion is immediately filtered using a Millipore All-Glass Filter Apparatus and a Gelman Metricel Alpha-8 filter paper. The filter paper is pre-soaked in ethanol before being used to collect the ink particles in order to prevent any weight change of the filter paper during filtration. The filter paper is dried and weighed before and after collecting the particles.

The filter paper with the ink sample is placed in a polypropylene beaker, covered with 30 milliliters of aqua regia, and placed over a boiling water bath. The aqua regia dissolves the filter, the metallic particles, and most of the oxide particles. The solution is evaporated to near dryness. Five milliliters of 24 percent hydrofluoric acid is added to dissolve silica and any remaining oxide particles and the solution is evaporated over boiling water bath to near dryness. Since insoluble fluorides sometimes form during this step, a second treatment with aqua regia is carried out to bring all materials into solution. The solution is evaporated down to 10 milliliters and diluted with deionized water in a 100 milliliter flask. 


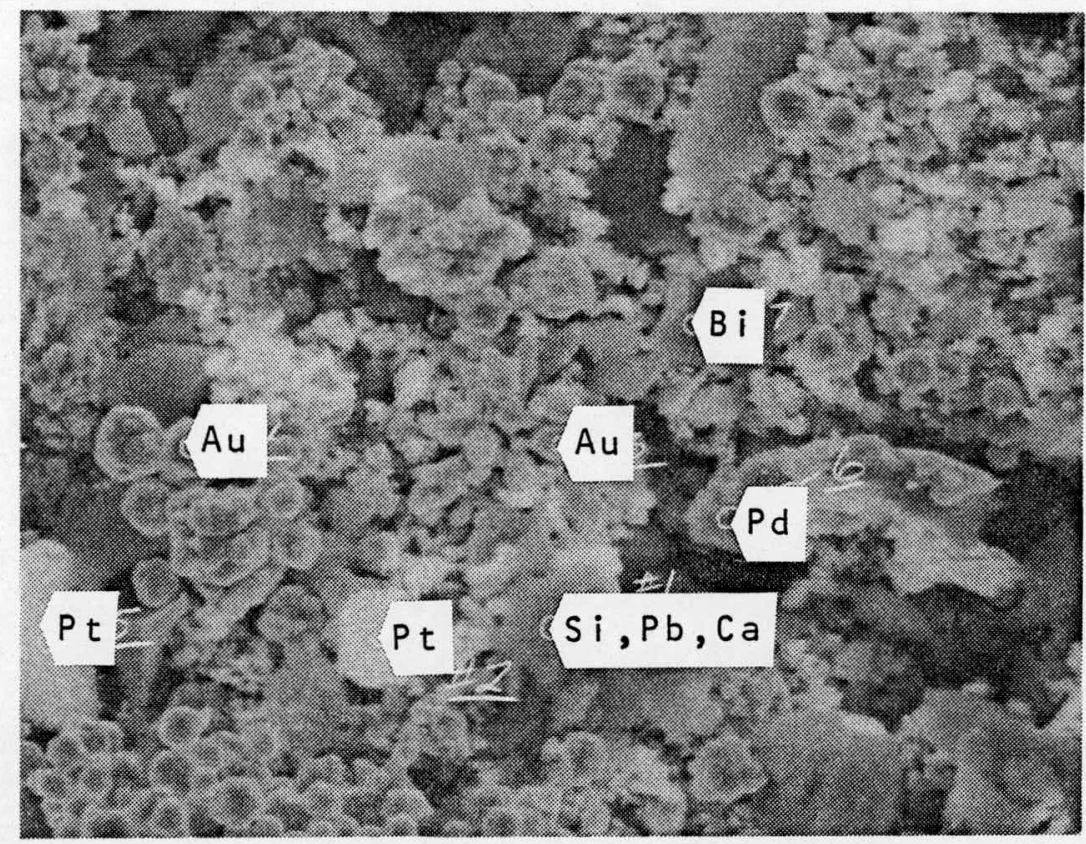

du Pont 8653 , Lot 405183 (3000x)

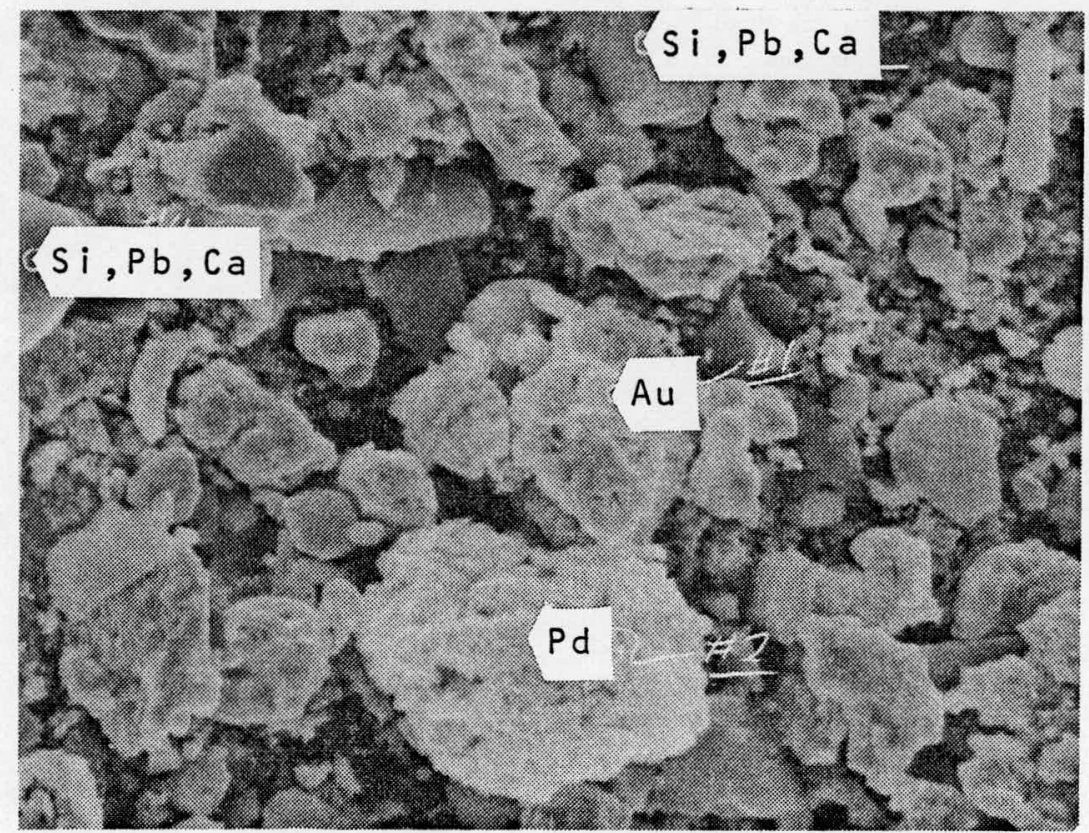

ESL 5800B, Lot 497-7A (3000X)

Figure 3. SEM/EDAX Analysis of Thick Films 


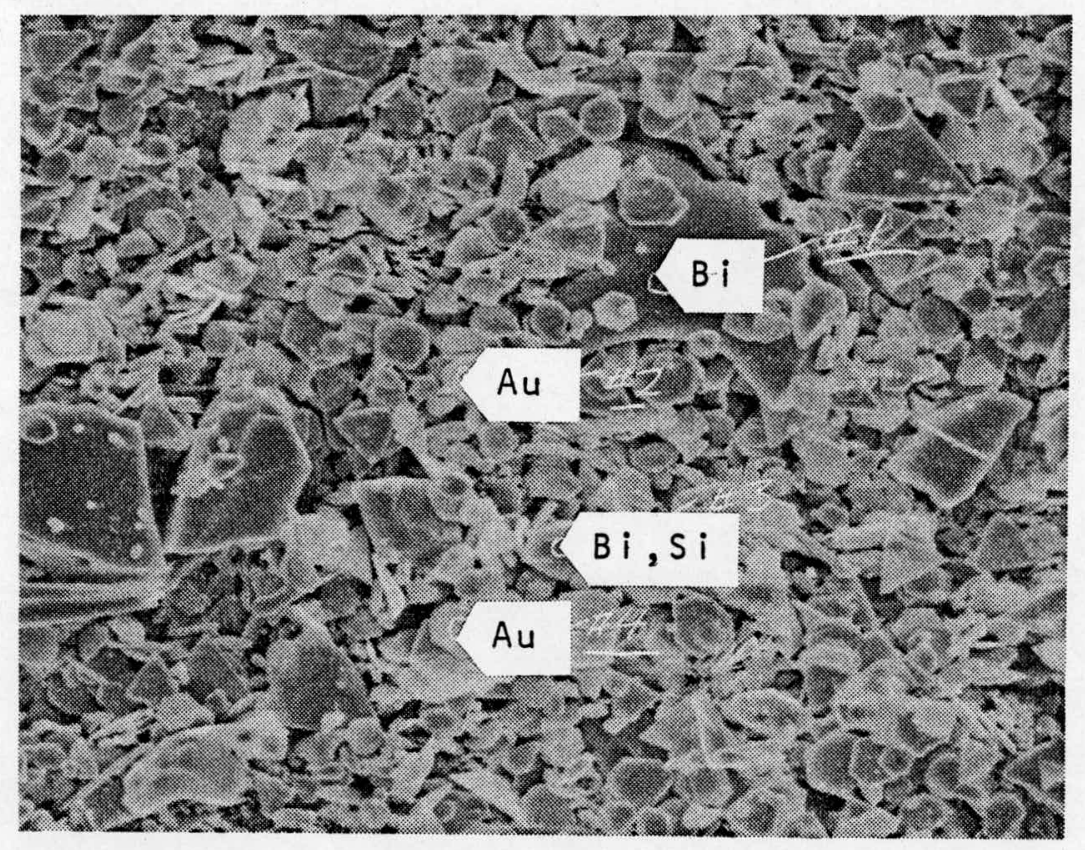

TFS 3007 , Lot 4042B (1000X)

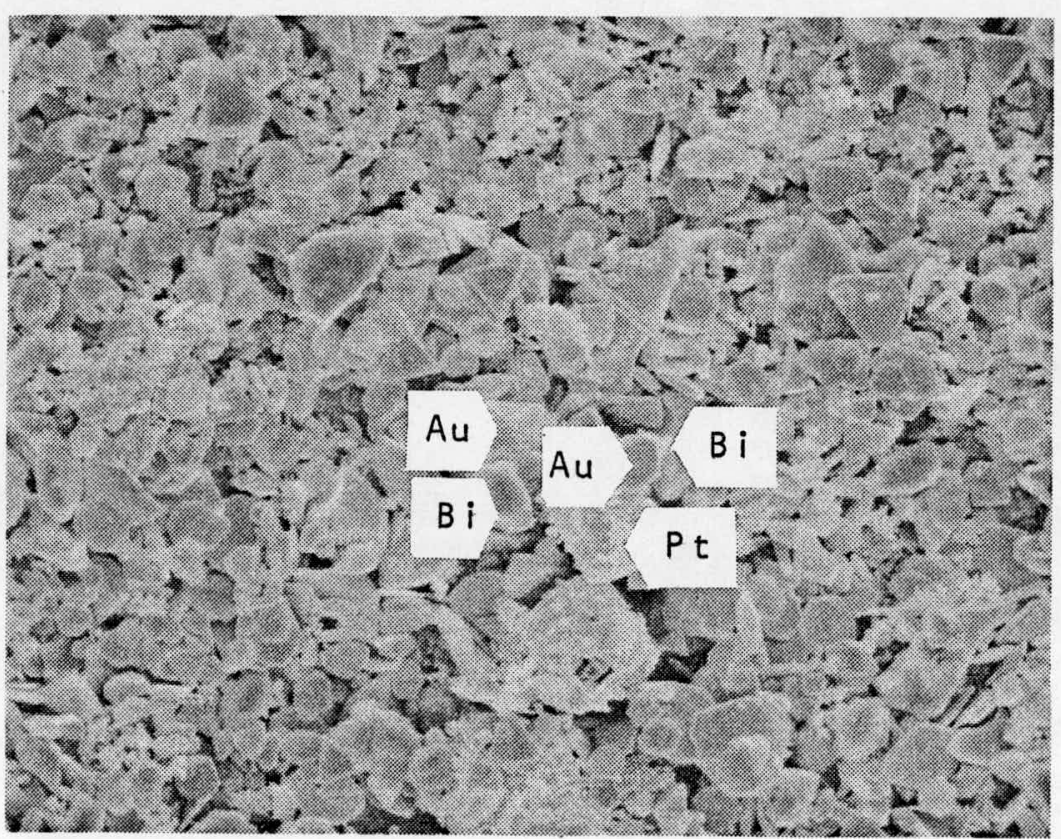

TFS 3104, Lot 4071B (1000X)

Figure 3. Continued. SEM/EDAX Analysis of Thick Films 

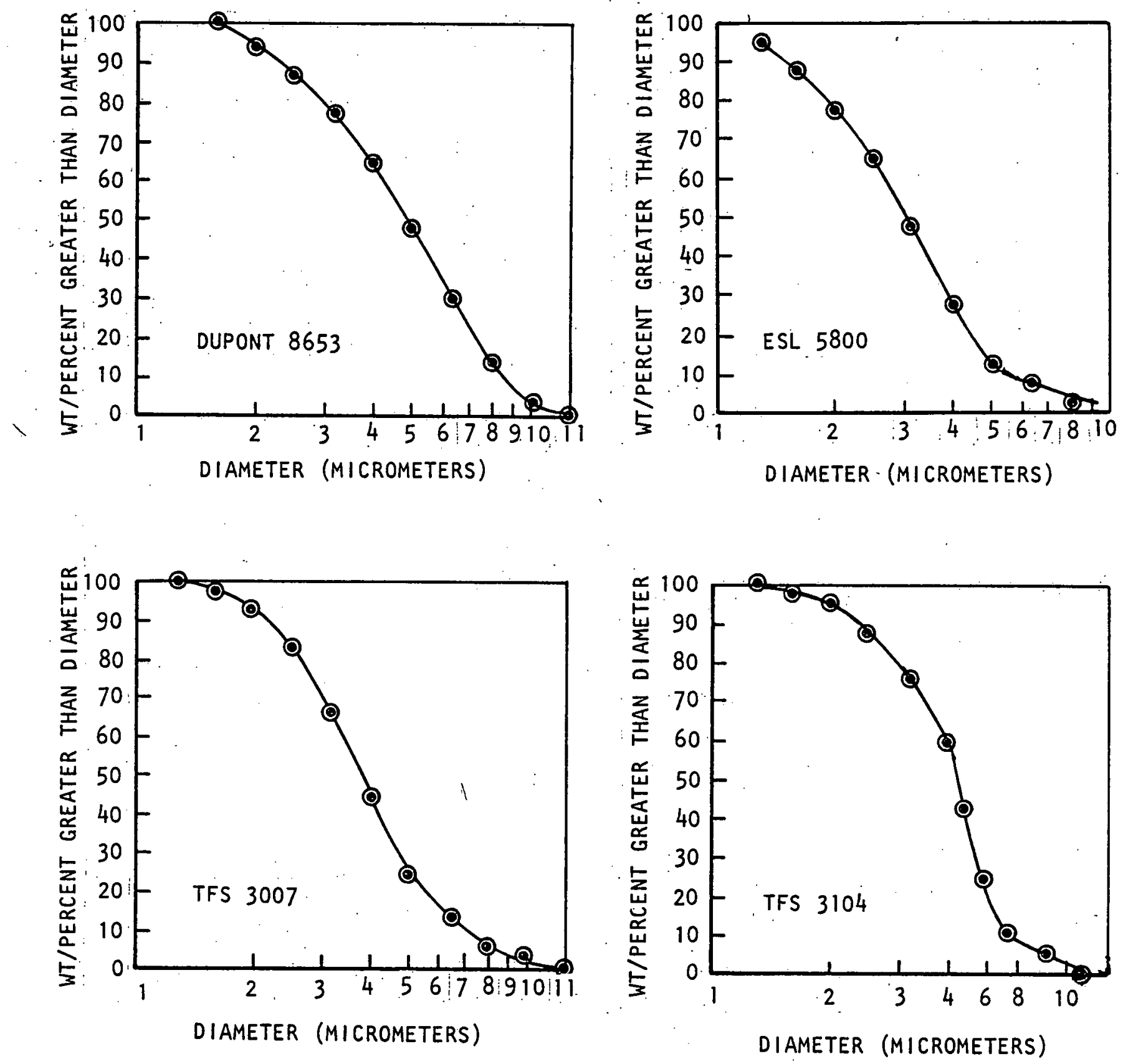

Figure 4. Particle Size Analysis by Coulter Counter 
For the atomic absorption measurement, a piece of filter paper is run through the sample preparation process to provide a blank. Any absorption readings obtained with this solution are subtracted from the sample reading. Each element to be analyzed by atomic absorption has a detection limit and a concentration range where the absorption measurements are linear. The stock solutions obtained from the sample preparation process must be diluted to the appropriate concentration range depending on the element to be analyzed (Table 3 ).

\section{ACCOMPLISHMENTS}

This work has shown thermogravimetric analysis to be the most useful in the analysis of the organic constituent. Pyrolysis-GC, IR, and mass spectrometer analyses furnish more detailed information on the composition of the organic but this information has no bearing on the properties of the fired film and very little bearing on the processing qualities of the ink. Thermogravimetric analysis determines the weight percent vehicle (volatile below $250^{\circ} \mathrm{C}$ ), weight percent binder (volatile above $250^{\circ} \mathrm{C}$ ), and weight percent inorganics. (Drying after printing is usually done at $100^{\circ}$ to $150^{\circ} \mathrm{C}$.)

Specimen preparation methods were developed allowing the inorganic constituents to be analyzed by atomic absorption spectrophotometer (AA). The $\mathrm{AA}$ is the fastest and most accurate way available to obtain a quantitative elemental analysis of the inorganics.

The Coulter counter was shown to be a convenient method of measuring the particle size distribution of the inorganics. The maximum particle size cannot exceed the dimensions of the screen used in the screen printer.

The recommendation is made that TGA, AA, and Coulter counter tests be performed on conductor inks to assure lot to lot uniformity for receiving inspection.

\section{FUTURE WORK}

Thick film inks are available for use as resistors and dielectrics in addition to conductors. Resistors in particular are very complicated in their conduction mechanism and chemical composition. If the use of thick film technology in production circuits is to become a reality, much work will need to be done to understand these other materials. 
Table 3. Atomic Absorption Analysis of Thick Film Conductor Inks

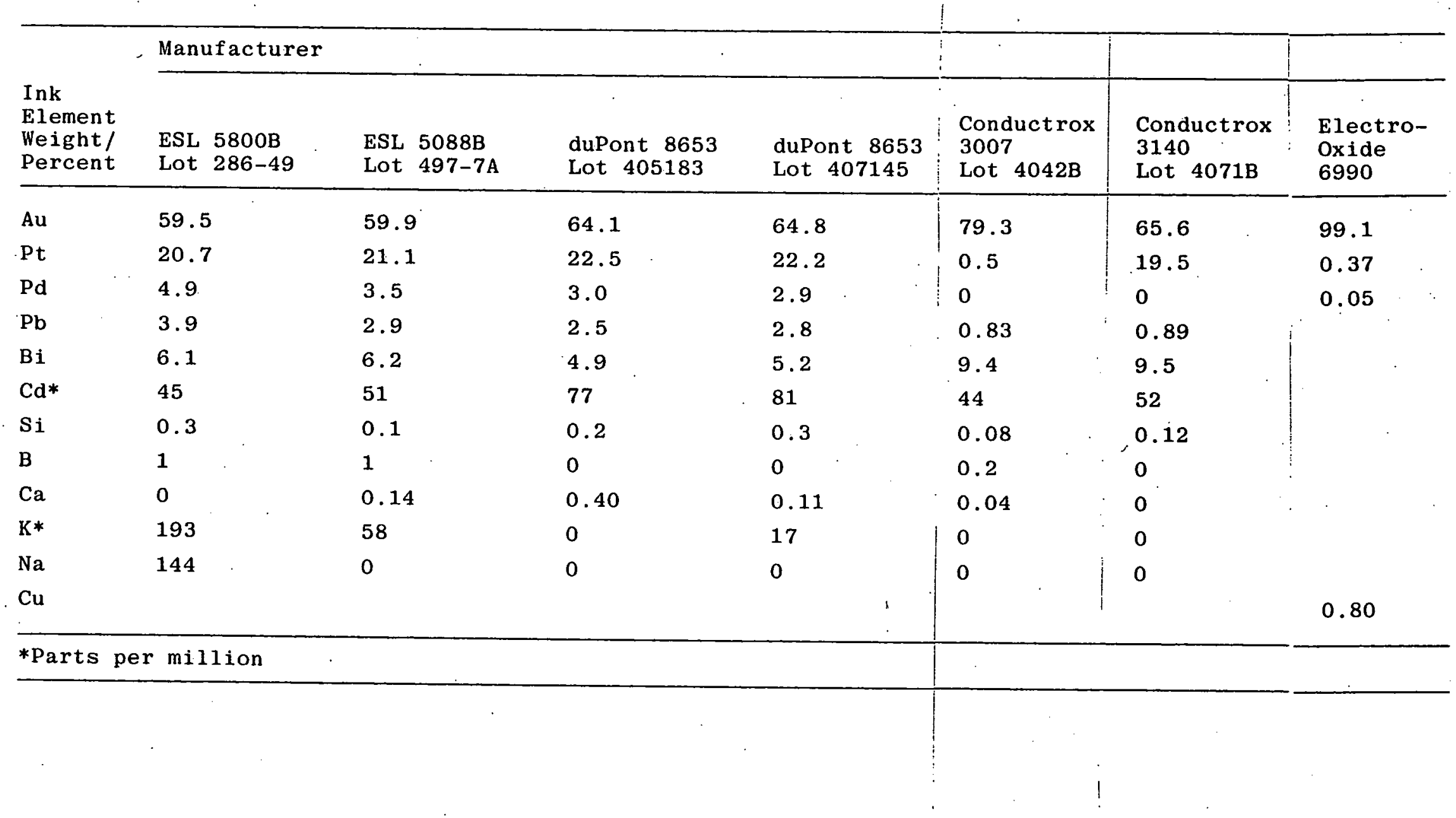




\section{REFERENCES}

${ }^{1}$ G. A. Swartz, Thick Film Networks (Final Report). UNCLASSIFIED. Bendix Kansas City: BDX-613-363, January 1972.

${ }^{2}$ M. V. Coleman, "Evaluation Methods for Examination of Thick Film Materials," Proceedings of Conference on Hybrid Microelectronics. Conference Proceeding Number 27. England: IEEE, September, 1973 , p 221.

${ }^{3}$ A. C. Buckthorpe, "Degradation of Thick Film Conductor Adhesion," Proceedings of Conference on Hybrid Microelectronics. Conference Proceeding Number 27. England: IEEE, September 1973, p 61.

${ }^{4} \mathrm{~F}$. Hailes and W. A. Crossland, "The Relationship Between the Thick Film Conductor and Substrate and Its Influence on Conductor Properties," Proceedings of the International Electronics Packaging and Production Conference. England: IEEE, October 1971, p 241 .

$5 \mathrm{~J}$. R. Larry, "Palladium-Silver Conductors with High Adhesion,". Proceedings, Electronic Components Conference. IEEE, 1973, $\mathrm{p} 161$.

${ }^{6} \mathrm{~L}$. J. Brady, "Relation of Particle Size of $\mathrm{RuO}_{2}$ in Cermet Resistor Inks to the Electrical Properties of Fixed Resistors," Proceedings, Parts, Materials, and Packaging. IEEE, December 1970, $\mathrm{p} 144$.

${ }^{7}$ B. Walton, "Principles of Thick Film Materials Formulation," Proceedings of Conference on Hybrid Microelectronics. Conference Proceeding Number 27. England: IEEE, September 1973, p 40.

${ }^{8} \mathrm{D}$. L. Herbst and M. Greenfield, "Theory of Conduction in Thick Film Conductors," Proceedings of the International Electronics Packaging and Production Conference. England: October 1971. 


\section{BIBLIOGRAPHY}

Brady, L. J., "The Mechanism of Conduction in Thick Film Cermet Resistors," Proceedings of Electronic Components Conference, IEEE , 1967.

Burks, D. P., "Reliability of Solder Connected Thick Film Hybrids," Reliability Physics, IEEE Symposium, 1973.

Fuller, G. L., "Microstructive Development in Thick Film Resistors," Ceramic Bulzetin, Abstract, 15 April 1973.

Hilson, D., "Development and Testing of Commercial Ink," Proceedings of Electronic Components Conference, IEEE, 1973.

Hitch, T. R., "Phase Morphology and Adhesion in Thick Film Conductor Inks," Proceedings, ISHM Symposium, 1971.

Holtze, R. F., "Properties of Conductive Thick Film Inks," NASACR-126973, NTIS CSCL2OL.

Hoffman, Bacchetta, and Frederick, "Adhesion of Platinum-Gold Glaze Conductors," Parts, Materials, and. Packaging IEEE Transactions, 1965,1 .

Jacobsen, L., "Testing for Adhesion of Hybrid Parts," Proceedings, IEEE and EIA Electronics Components Conference,. 1971.

Kazmierowiez, C. W., "Where is Resistance in a Thick Film Resistor Network," Ceramic Bulletin (Abstract), 15 September, 1973 .

Keleman, D. G., "Metallurgical Aspects of Thick Film Technology," Metallurgical Transactions 1, 1970.

Melan, E. H. and A. H. Nones, "The Glaze Resistor-Its Structure and Reliability," Proceedings of Electronic Components Conference, IEEE, 1964.

Miller, L. F., Thick Film Technology and Chip Joining, Gordon and Breach Publishers, 1972.

Payne, D. A., "Thick Film Dielectrics with Glass Bonded Electrodes: Influences of Interfacial Reaction Layers on Composite Impedance," Ceramic BulZetin (Abstract) 15 April 1973.

Peluso, R. F., "Reliability Considerations for Wire Bonding Thick Film Hybrids," Proceedings, International Microelectronics Symposium, 1973. 
Polinski, P. W., "Consideration of Conduction Mechanism Formation in Thick Film Resistors Exhibiting Stability under High Electromagnetic Stress," Electronics Component Conference, 1973 .

Rikoski, R. A., "Hybrid Microelectronic Circuits," The Thick Film, Wiley-Interscience, Publishers, 1973.

Shewchun, J., "Properties of Thick Films as Revealed by Selective Chemical Etching," Journal of Vacuum Science and Technology, July, August, 1974.

Short, A. O., "Galvanic Effects in Thick Film Dielectric Layers," Ceramic Bulzetin (Abstract), 15 September, 1973.

Swayne, R:, "Thermal Behavior of Thick Films," Solid State Technology, Volume 16, Number 6, June 1973.

Vest, R. W., "Conduction Mechanisms in Thick Film Microcircuits,." National Technical Information Service, AD 775639.

Williams, L., Jr., "Evaluation Tests of NASA Thick Film Resistors Over a Six Year Period," American Ceramic Society BuzZetin, Volume 51, Number 4, April 1972.

Williams, L., Jr., "Evaluation Tests on Commercial Thick Film Resistors," American Ceramic Society Bulletin, Volume 51, Number 4, April 1972.

Thick Film Dielectric Glaze Ink and Paste Formations used in Microelectronics Technology, National Technical Information Service, AD-733253. 


\section{DISTRIBUTION}

Copy

R. Bulcock, ERDA-KCAO

S. L. Erickson, SLA

D. R. Johnson, SLA

J. C. Russell, SLA

J. D. Corey, D/554, BD50

$5-6$

L. Stratton, D/554, 2C 44

R. P. Frohmberg, D/800, 2A39

7-9

W. H. Deterding, D/814, 2C43

D. L. Stoltz, D/814, 2C43

G. L. MacCurdy, D/816, SG-3

W. J. Stone, D/816, SG-3

D. H. Brewer, D/816, SG-3

A. O. Bendure, D/842, MD 40

J. S. Bosnak, D/842, MD40

16

G. A. Swartz, D/842, MD40

17

R. E. Kessler, D/865, 2C40 